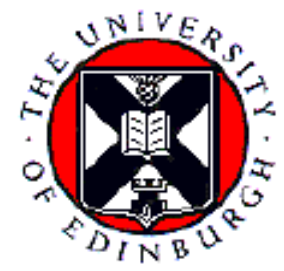

\title{
Industry Cost of Equity Capital: UK Evidence
}

\author{
Alan Gregory \\ University of Exeter \\ $X f i$ Centre for Finance and Investment \\ University of Exeter Business School \\ and \\ Maria Michou \\ University of Edinburgh \\ University of Edinburgh Business School
}

Paper Number: 07/08

February 2009

\section{Address of Correspondence:}

Alan Gregory

Xfi Centre for Finance and Investment, University of Exeter Business School, University of Exeter, Exeter, EX4 4PU, UK

Telephone number: $++44(0) 1392263220$

Email: A.Gregory@exeter.ac.uk 


\title{
Industry Cost of Equity Capital: UK Evidence
}

\begin{abstract}
This paper explores the industry cost of equity capital for the UK. We replicate the Fama and French (1997) US analysis for UK industries, but additionally investigate the industry cost of equity capital obtained from a conditional CAPM, the Cahart (1997) four factor model, and the Al-Horani, Pope and Stark (2003) R\&D model. In line with the Fama-French US results, the out of sample performance of all the models is disappointing Whilst the FF3F model has a somewhat higher explanatory power than the CAPM in terms of explaining past returns, the SMB and HML factor slopes show considerable variability through time. However, all our models of the cost of equity capital in the UK outperform a simple "beta one" model, a result that has implications for the regulatory process. There is also some evidence to suggest that a conditional CAPM may be of interest to regulators. The new R\&D model of Al-Horani et al clearly has potential, in that over the limited period for which data is available it yields return errors not dissimilar to those found under the FF3F model, but exhibits slope coefficients on the fourth R\&D factor that seem to be relatively stable.
\end{abstract}

Keywords: Cost of capital, Fama and French, asset pricing, book-to-market, size

JEL Classification: G11, G12, G15, G31

Acknowledgements: The authors would like to thank participants at the Xfi Cost of Capital Conference (supported by the Competition Commission), Exeter, June 2007, Richard Harris and the anonymous referee together with Martin Walker, Editor, for their helpful comments on earlier drafts of this paper 


\section{Industry Cost of Equity Capital: UK Evidence}

\section{INTRODUCTION}

The US study of industry cost of equity capital by Fama and French (1997) paints a fairly bleak picture of the prospects for being able to estimate the cost of capital of any firm or industry with any degree of accuracy. Indeed "fairly bleak" is an understatement, given the authors conclude that "estimates of the cost of equity are distressingly imprecise". They go on to describe that their message is that project valuation is a task "beset with massive uncertainty". Apart from a preliminary study by Gregory and Rutterford (2001), Al Horani, Pope and Stark (2003), who use various factor models to estimate risk premia for industry portfolios based on their research and development activity (R\&D), and Michou, Mouselli and Stark (2007), who examine how well Fama and French factors explain average returns on size, book to market and industry sorted portfolios, there appears to be little work on industry cost of capital in the UK. In addition to the standard corporate problem of capital budgeting, there are major policy concerns with cost of capital estimation. The UK regulatory process attaches major importance to estimates of cost of capital, as it is central to the pricing formula used to set prices in regulated industries (e.g. water, electricity, gas and airports) and also forms one of the components of the "profits test" used in market investigations by the Office of Fair Trading and the Competition Commission. If there is great uncertainty about the true cost of equity capital, then there are potentially serious policy implications not only for the regulated sector of firms, but also for any attempts to measure "excess" profitability in the context of market investigations.

In this paper, we focus on just the equity cost of capital for UK firms. Uncertainty about the cost of equity capital comes from three sources: first, uncertainty about the appropriate model to use in estimation; second, uncertainty about the factor prices associated with various models; third, uncertainty surrounding the estimation of factor loadings, or slope coefficients. The debate about factor prices, most notably the market risk premium, has been the subject of extensive discussion elsewhere in the literature (see, for example, Dimson et al (2002, 2006, 2007), Gregory (2007) and Vivian (2007)) and so we do not pursue that issue here. In this paper, we follow Fama and French 
(1997) and concentrate our efforts on the uncertainty surrounding the choice of model and the estimation of slope coefficients. Specifically, we examine the properties of static and rolling versions of the capital asset pricing model (CAPM), the Fama-French (1993, 1995, 1996) three factor model (3FM), and the Cahart (1997) four factor model (4FM), conditional versions of the CAPM and 3FM model, and finally a simple market adjusted returns model (MAR), equivalent to assuming beta is unity in the CAPM.

The remainder of the paper is organised as follows: Section 2 presents a brief discussion of the CAPM, three and four factor models; in section 3 we discuss the details of the research method outlined above and the data set used; in Section 4 we explain and discuss the results; and in Section 5 we draw some conclusions from the analysis.

\section{THE MODELS INVESTIGATED}

The basic models we investigate can be described as special cases of the 4FM. The 4FM itself can be described as:

$$
R_{p t}-R_{f t}=\alpha_{p}+\beta_{p}\left(R_{m t}-R_{f t}\right)+s_{p} S M B_{t}+h_{p} H M L_{t}+w_{\mathrm{p}} W M L_{t}+\varepsilon_{\mathrm{pit}}
$$

\footnotetext{
$R_{p t} \quad$ is the return for portfolio $p$ for period $t$;

$R_{f t} \quad$ is the risk-free return for period $t$;

$a_{p} \quad$ is the intercept term for portfolio $p$;

$\beta_{p}, s_{p}, h_{p}$ and $w_{p} \quad$ are the exposures of portfolio $\mathrm{p}$ to $\left(R_{m}-R_{f}\right), S M B, H M L$, and $W M L$ respectively;

$R_{m t}$ is the return on the market (as proxied by the FTASI) for period $t$

$S M B_{t} \quad$ is the size risk factor for period $t$;

$H M L_{t} \quad$ is the book to market risk factor for period $t$;

$W M L_{t} \quad$ is the momentum factor for period $t$; and

$\varepsilon_{i t} \quad$ is an error term for portfolio i for period t.
} 
We also compare an alternative factor model of returns following Al-Horani et al (2003) where the momentum factor in the above model is replaced by a research and development (R\&D) factor, as follows:

$$
R_{p t}-R_{f t}=\alpha_{p}+\beta_{p}\left(R_{m t}-R_{f t}\right)+s_{p} S M B_{t}+h_{p} H M L_{t}+r_{\mathrm{p}} R D M N R D+\varepsilon_{\mathrm{pit}}
$$

The R\&D factor (RDMNRD) represents the difference between the value-weighted average of a portfolio of firms with $R \& D$ expenditures, and the value weighted average of a portfolio of firms without $R \& D$ expenditures (the construction of the factor is described below).

These models can be estimated for each industry portfolio $p$ over the full $t$ data periods, when under null hypothesis of no-abnormal performance and a complete description of returns the average $\alpha_{p}$ coefficient should be equal to zero. In effect, the 3FM model amounts to a special case of (1) above where the factor loading on $w$ is constrained to be zero, and the CAPM is a special case where the loadings on $s, h$ and $w$, respectively are restricted to be zero. Which of the CAPM, 3FM and 4FM models are most appropriate depends on one's reading of the evidence to date. The potential shortcomings of a conventional CAPM are well known, with size effects in particular posing a problem for the CAPM. Nonetheless, there is some evidence that estimating either a conditional CAPM, or a model using longer period betas, may mitigate some of these shortcomings. For example, Kothari, Shanken and Sloan (1995) show that by using annual returns beta risk is priced, although firm size also has a role in explaining returns, whilst Kim (1995) shows that correcting for the errors in variable problem attributable to the use of estimated betas, beta is important in explaining the crosssection of US stock returns and firm size has an important, though diminished, role. Jaganathan and Wang (1996) show that if beta is allowed to be conditional on an economic risk factor, and the 'market' portfolio includes the value of human capital, a 'conditional' CAPM holds. Both Roll and Ross (1994) and Ashton and Tippett (1998) show that estimates of beta are extremely sensitive to mis-specification of the market portfolio. In particular, the latter show that such mis-specification can result in researchers reaching an incorrect conclusion that factors such as book-to-market ratios 
are significant in explaining returns. Despite some of these more positive comments about the CAPM, none of the studies show that the simple version of the CAPM, typically employed by companies, competition authorities and regulators, holds. Either "size effects" are important, or we need to estimate a conditional CAPM possibly using a complex definition of the market portfolio. In addition, the problem of beta being highly sensitive to mis-specification of the true market portfolio may be impossible to address.

The returns to momentum are well-documented in the US, the UK and continental European markets (Liu et al [1999], Jegadeesh et al [1994, 2001], Lesmond et al [2004] though see also Tonks and Hon [2003]). In general, momentum remains something of a puzzle, and although a recent paper by Liu (2006) provides evidence consistent with US momentum returns being rationally-priced liquidity risk, no such evidence exists for the UK. Nonetheless, for completeness we investigate whether or not a 4FM has anything to contribute to our understanding of UK cost of capital. If momentum returns are anomalous, we might expect a momentum factor to explain the cross-section of returns within any given time period, but be poor in predicting future returns and, in addition, for the slope coefficients on the momentum factor to exhibit parameter instability.

The R\&D model represents an extension to the FF3F model. Al-Horani et al (2003) show that including a factor designed to capture the effects of $R \& D$ expenditure can significantly improve the explanatory power of the FF3F model within the UK, and critically alters the expected risk-adjusted returns across industries. The intuition behind the model is twofold: first, that investment in R\&D (or "knowledge") assets may have a risk profile and pay-off pattern that differs from that of physical assets, and second, that accounting conservatism implies a different relationship between market value and book value for firms that expend resources on $R \& D$ activity compared to those that do not.

We estimate the models implied by (1) and (2) in two ways. First, we assume parameters are constant over the entire time period of our study (1975-2005, but 19912005 in the case of the R\&D model). Tests for statistical inference can then be set up in the usual way. Second, we can allow for time-varying factor loadings by estimating 
rolling coefficients. The regressions are run for successive over-lapping 60 month periods.

An alternative approach is to allow for time-varying factor loading by implementing either a conditional version of the CAPM (Ferson and Schadt, 1996) or a conditional version of the 3FM model which allows for shifts in industry size and book to market variables. Specifically, the conditional CAPM model we estimate is:

$$
R_{p t}-R_{f t}=\alpha_{p}+\beta_{0 p}\left(R_{m t}-R_{f t}\right)+\beta_{1 p}^{\prime}\left(z_{t-1}\left[R_{m t}-R_{f t}\right]\right)+\varepsilon_{\mathrm{it}}
$$

where $z_{t-1}$ is a vector of instruments for the information available at the beginning of month $\mathrm{t}$ (i.e the end of month $\mathrm{t}-1$ ) and $z_{t-1}=Z_{t-1}-E(Z)$ is a vector of deviations of instruments from their unconditional means. Instruments used are: the lagged dividend yield, the lagged treasury bill rate, and the lagged term structure (difference between long gilt rate and the treasury bill rate).

For the conditional version of the 3FM we run the same regression as that in Fama and French (1997):

$$
\begin{aligned}
R_{p t}-R_{f t}=\alpha_{p}+\beta_{p}\left(R_{m t}\right. & \left.-R_{f t}\right)+s_{1 p} S M B_{t}+s_{2 p} \ln \left(M E_{t}\right) S M B_{t}+h_{1 p} H M L_{t} \\
& +h_{2 p} \ln (B E / M E)_{t} H M L_{t}+\varepsilon_{\mathrm{pit}}
\end{aligned}
$$

For the R\&D model, we are only able to undertake estimation for the period post July 1991, given the point at which R\&D expenditure reporting became mandatory in the UK. As with the 4F model, only unconditional versions of the model are estimated.

For each of these models we report slope coefficients and conventional significance tests. For the rolling coefficient models, to test the hypothesis that the coefficients are significantly different from zero requires a t-statistic that is robust to the overlapping nature of the data, with the relevant test statistic being estimated by a Newey-West (1987) procedure allowing for the 59 overlapping observations. In addition, we wish to test for parameter stability. We conduct two tests here. The first follows Fama and French (1997, p. 158) and recognises that if the true slopes are stationary, the variance of the time series slope is the sum of the variance of the true slope plus the variance of 
the estimation error. The (unobserved) variance of the true slope is found by subtraction, but set to zero if negative. We also separate our sample into two equal periods (the number of months varies as some industries do not exist for the entire sample period) and estimate Wald statistics to test for performance differences between first and second halves, again allowing for overlapping observations using a NeweyWest procedure. ${ }^{1}$ The Wald test can be viewed as testing for any systematic change in the coefficients, although simply splitting the data into first and second halves may be viewed as a somewhat crude test.

\section{DATA}

\subsection{Data and Sample Selection}

Data is sourced from Datastream and the London Share Price Database (LSPD) for the UK equity market over a sample period from 1975 to 2005 and the SEDOL number is used to match the companies between the two databases. Care was taken to incorporate data for all companies, including de-listed companies either due to bankruptcy, acquisition or various other reasons in order to minimise survivorship bias.

The ratio of book value to market value $(B M)$, is defined as equity capital and reserves (Datastream accounting item: 305) minus total intangible assets (Datastream accounting item: 344), divided by the market capitalisation of the firm's equity. Returns for each company, including dividends and adjusted for changes in capital structure, are from the London Business School Database (LSPD).

Following the Gregory, Harris and Michou (2001, 2003) methodology, portfolios are formed each July on an annual basis. For each year, $t$, of the sample period portfolios include all companies for which the above book-to-market ratio can be identified on December of year $t-1$, and which have at least one month's return for the year starting at July of year $t$. It should be noted that the six month lag is adopted in order to allow a minimum of six months between the close of the fiscal year end and the time when the market receives the accounting information for that year.

\footnotetext{
${ }^{1}$ This approach is used in Gregory and Whittaker (2007) and the authors are grateful to Richard Harris for these suggestions on significance testing.
} 


\subsection{Portfolio Formation}

\section{Industry portfolios:}

To evaluate the performance of industry portfolios, we allocated stocks in our sample into 35 industry portfolios. We report value weighted returns for each industry portfolio, where each stock is weighted in proportion to its market capitalisation at the date of portfolio formation. The portfolios are formed from July 1975 to December 2005 using LSPD G17 codes and FTSE Industrial Classification Benchmark (ICB). The Industries are defined in Appendix A. Summary statistics for the industry portfolios are reported in Table $1 .^{2}$ One issue is that of industry classification. These classifications have changed at several points between the start and end periods used in our analysis, and so we need to settle on a particular cut-off. As such, we choose the most recent definition, which allows us to include all new industries that have been created during our sample period (for example, utilities in their current form only arose post privatisation). We drop investment trusts, and where there are severe data limitations, combine some categories (oil and oil services), so we have a total of 35 industries in our sample. An earlier version of this paper used 38 industry groupings (including investment trusts), but these data limitations for some industries led us to prefer the 35 industry grouping. We also ran tests using the 20 industry groupings found in Michou et al (2007). The results from these tests are not inconsistent with, but somewhat weaker than, the results reported here. Our view is that if the aim is to obtain results that are of value to market participants and to regulators, the finer industry partition of 35 industries is probably of more interest, and so we concentrate on that grouping in this paper.

\section{Fama and French, momentum and R\&D portfolio formation:}

To replicate the factors for the UK, we form three-factor portfolios similar to those described in Fama and French (1993) but using a UK proxy for the NYSE break points that they employ. In US studies, the NYSE median is used to set size breakpoints for the six intersecting size and book-to-market portfolios, and the NYSE universe is used to set book-to-market portfolio cut-offs, which are formed on the basis of the top $30 \%$

\footnotetext{
${ }^{2}$ Note that we also estimate the results from using equally weighted portfolios. As the results are similar, but somewhat weaker, when equally weighted portfolios are used, we do not report such results separately.
} 
("High" or "Value"), next 40\%, and bottom 30\% ("Low" or "Growth") of firms by book-to-market ratio. In constructing these UK factors, as a proxy for that cut-off we use the median firm in the largest 350 companies (excluding financials) by market capitalisation for the size breakpoint, and use the top 350 firms to set the cut-offs for sorting all companies into book-to-market portfolios. So in total we end up with the following six portfolios, where " $\mathrm{S}$ " denotes small, "B" denotes big, and " $\mathrm{H}$ ", " $\mathrm{M}$ " and "L" denotes high, medium and low book to market respectively: S/H; S/M; S/L B/H; $\mathrm{B} / \mathrm{M} ; \mathrm{B} / \mathrm{L}$. The usual SMB and HML factor portfolios (see below) are then formed using the universe of UK stocks for which market capitalisation, returns, and book-tomarket ratios can be constructed from any source. We use December year $t-1$ accounting data and end of June market capitalisation data. As in Fama and French, the portfolios are formed at the beginning of July in year $t$ and financial firms are excluded from portfolios.

Following Fama and French, (1993 and website updates), the factors are constructed using the 6 value-weighted portfolios formed on size and book-to-market as described above. SMB (which is an abbreviation of "Small Minus Big") is the average return on the three small portfolios minus the average return on the three big portfolios, whilst HML (an abbreviation of "High Minus Low") is the average return on the two value portfolios minus the average return on the two growth portfolios. For the "market" return, $R m$, we use the total return on the FT All Share Index, and for $R f$, the risk free rate, we use the one month return on Treasury Bills.

To calculate the momentum returns, we rank stocks at the end of December each year based on their ranking period returns and then group the stocks into three value weighted portfolios based on these ranks. The difference between the value weighted average of firms with the highest group of eleven month returns lagged one month (winners), and the value weighted average of firms with the lowest group of eleven month return lagged one month (losers) gives the fourth factor, winners minus losers (WML). 
To calculate the R\&D factor (RDMNRD), we follow the Al Horani, Pope and Stark (2003) method, where each of the three book to market portfolios ${ }^{3}$, (L, M and H) have been divided into two sub groups: one comprising firms with R\&D activity and one comprising firms without reported $\mathrm{R} \& \mathrm{D}$ activity. The L, M and $\mathrm{H}$ sub-groups with R\&D activity are referred to as LRD, MRD and HRD respectively. Similarly, the L, M and $\mathrm{H}$ sub-groups with no reported $\mathrm{R} \& \mathrm{D}$ activity in the relevant year are referred to as LNRD, MNRD and HNRD respectively. The RDMNRD factor is defined as the difference between the average of the value-weighted with-R\&D portfolio returns, $(\mathrm{LRD}+\mathrm{MRD}+\mathrm{HRD}) / 3$, and the average of the value-weighted returns on the withoutR\&D portfolios, (LNRD+MNRD+HNRD)/3.

\section{RESULTS}

\subsection{Background factors}

Our first results in Table 2 simply report the average monthly returns, standard deviations and implied standard errors for the factors, together with a correlation matrix. On the latter, note that although there is little evidence of significant correlations within the three factors, the momentum factor exhibits negative correlation with both SMB and HML factors. Compared to the Fama and French (1997, Table 1) estimates (which are for the period 1963-1994) we record a somewhat higher market risk premium, a considerably lower SMB premium, and a higher HML premium. The annualised standard errors are not dissimilar from those reported in that paper, but still imply considerable uncertainty about the size of premia. Whilst we would strongly advocate the use of longer-run data in making estimates of the premia, the UK data available does not allow estimation of the HML factor before 1975. We are thus confined to base our analysis on this run of data. The evidence (based on a conventional +/- two standard error rule) suggests that neither the SMB return nor the WML return are significantly different from zero, although the HML return is. Nonetheless, all the standard errors suggest a good deal of uncertainty about the scale of the factor returns, and that the uncertainty is marginally larger for the UK than the US (as one might expect given the smaller population of UK firms).

\footnotetext{
${ }^{3}$ Note, though, that we employ the top 350 company cut-offs for these book-to-market portfolios described above, whereas Al-Horani et al (2003) use the entire range of London stocks in setting their book-to-market cut-offs.
} 
Data for the R\&D factor are necessarily limited by the comparatively short period for which firms have been required to report $R \& D$ expenditure. For comparison, we report means and standard deviations for RDMNRD and the other factors over the shorter period for which data is available. We record a substantial and significant return on the R\&D factor. With regard to correlations with the market factor and the SMB factor, our figures are consistent with (but somewhat smaller than) the figures reported in AlHorani et al (2003), whose data period ends in mid-2001. However, we find a negative correlation between HML and RDMNRD. This may be attributable to the different behaviour of technology stocks (which one would expect to be high R\&D) in the runup to the technology stock "bubble", that would have been captured in their paper, compared to behaviour of those stocks between 2001 and the end of 2005, which will only be present in our paper. Notably, during that period, technology stocks performed poorly whilst high book to market (or "value" stocks) performed well. However, it is more likely that the difference between our results and the Al-Horani et al (2003) results lie in the establishment of the cut-offs for size and book to market ratios. Their paper use all stocks in establishing medians and cut-offs, whereas we use the largest 350 stocks, as described above. Given that Michou et al (2007) show that these portfolio formation techniques can have a marked impact on factor returns and correlations, it is not surprising that some of our results differ from those in Al-Horani et al (2003).

\subsection{Static regressions}

Table 3 shows the "static" (i.e. whole period) model estimates for each of the 35 industries for which we provide estimates. ${ }^{4}$ The CAPM results in the first group of columns shows that all beta coefficients are significantly greater than zero, that the mean beta is 0.902 , and that the mean alpha is zero. The number of significant alpha coefficients is in line with that which would be expected given a null hypothesis of no significant outperformance under the CAPM. The average adjusted R-squared is around $32 \%$. R-squared varies between industries, running from a minimum of 0.12 to a maximum of 0.51 . It is noticeable that the lowest R-squareds are found in two of the

\footnotetext{
${ }^{4} \mathrm{~A}$ full description of the industries is given in the appendix.
} 
regulated industries, which is troubling from a policy point of view, although to some degree this may be because these industries have shorter histories (as reported in Table 1). There is no evidence that the level of R-squared is associated with the number of firms in the industry. Turning to the 3FM, we see that beta estimates and inferences are similar to those under the CAPM, but 22 industries have significant positive loadings on SMB, with one negative loading, and have an average slope of 0.3 , whilst there are ten significant positive loadings on HML and three negative ones, with an average slope of 0.075 . The average alpha is zero, and the $35 \%$ average adjusted R-squared shows a small improvement over the CAPM figure. The pattern of individual industry R-squareds seems to follow that of the CAPM, in that high R-squareds and low Rsquareds are found in the same industries. The four factor model again produces similar inferences with regard to beta, but the inferences with regard to the significance of SMB and HML slopes change, although average loadings are similar. In particular, the number of significant positive loadings on SMB falls to 19, whilst two significant negative loadings appear. There are two significantly positive WML slopes, and six significantly negative ones. Turning to the 4 -factor R\&D model, the mean beta moves closer to unity, but the SMB loading remains similar to that under the FF3F and 4factor models, and the mean HML loading increases to 0.125 . Whilst the mean R\&D factor (RDMNRD) exposure is close to zero, 6 industries have significant positive loadings on R\&D while two have negative loadings. However, there is one significant positive alpha under this model but 4 significant negative alphas. The adjusted Rsquared is around $31 \%$, but the much shorter time period over which the model can be estimated means that this cannot reasonably be compared with the R-squared figures for the other models. Rather disappointingly, we note that in all cases the average Rsquareds for this UK study are considerably lower than Fama and French (1997, Table 2) find for the US. This almost certainly reflects the lower number of firms that make up the UK dataset. Last, although not reported in the Table for reasons of space, we note that none of the regulated industries (Ind 26, Telecoms; Ind 27, Electricity; Ind 28, Gas \& Water) show a significant loading on either SMB or WML factors. However, Telecoms loads significantly negatively on the HML factor, whilst Electricity loads positively ${ }^{5}$ in the 4 -factor model. In the R\&D model no significant loadings occur in respect of RDMNRD in any of these industries.

\footnotetext{
${ }^{5}$ The positive loading is only significant at the $10 \%$ level in a three factor model.
} 


\subsection{Time varying coefficients}

In Table 4, we attempt to shed some light on whether or not factor loadings change through time. It may be expected that some changes in industry factor loadings occur

in response to industry entry and exit, and also in response to changes in the industry average gearing. However, to the extent that optimal gearing levels are unlikely to change radically, and that there is no reason to suppose that new entrants have different systematic business risk from incumbents, one would not expect such changes to be particularly pronounced. The table shows the implied standard deviations of the true slopes of the various factors. These are estimated on the basis of the 60 month rolling regressions. The estimates give an idea of how far a current observation of the slope made from a rolling regression estimate might be from the true long term average, if slope coefficients are from a stationary distribution. In addition, we undertake a Newey-West test to examine whether the rolling coefficient estimates are significantly different from zero. Under the CAPM, all our industries have a significantly positive beta. Under the 3FM, the variability of beta is almost the same as that found under the CAPM, whilst there is considerable variability in SMB and HML slope coefficients. Some $60 \%$ of the sample has a significant positive loading on SMB, with $5.7 \%$ exhibiting a significant negative loading, and $34.3 \%$ of industries load significantly positively on HML whilst $20 \%$ load significantly negatively. Under the 4FM, results for the first three factors are broadly similar, although variability of slope coefficient for beta, SMB and HML are damped down somewhat. In addition, 14.3\% of industries load significantly positively onto WML, and $14.3 \%$ load negatively. Intriguingly, the WML factor has a little less slope variability than any of the other factors, although volatility is still significant. Under the 4 -factor $R \& D$ model, the shortened time period for analysis means that the slope variabilities are not directly comparable between models, but it is worth noting that the RDMNRD slope exhibits less variability than any of the beta, SMB and HML slopes. Furthermore, 20\% of industries load significantly positively onto $R \& D$, and $22.9 \%$ load negatively.

In general, our estimates show evidence of inter-temporal variation in factors as found by Fama and French (1997). Whilst our mean volatilities are generally a little higher than those found by Fama and French, we have a large percentage of industries where 
the variance of the true slope is zero. However, as Fama and French note, the time series variances of the rolling regression slopes are only well defined if the true slopes are stationary. A crude test for stationarity is to split the run of observations for any industry into two halves, and run a Newey-West test on a dummy variable for the second time period. This dummy variable shows up as being significant for $42.9 \%$ of the industry CAPM beta estimates, for $45.7 \%$ of the SMB estimates, and $34.3 \%$ of the HML estimates, whilst under the 4FM $54.3 \%$ of the sample show SMB exposure variation and $28.6 \%$ of the WML estimates exhibit significant time variation. ${ }^{6}$ No tests on an R\&D dummy were performed because of the short period over which data are available.

The broad picture that emerges from Table 4 is that whilst, for some industries, there is evidence of parameter stability, for others there is considerable time variability. This is, of course, rather unhelpful but if the coefficients move in a predictable fashion, then variability may not be a problem, although it would imply that a conditional model of asset pricing needs to be used. We investigate two conditional models here. The first is the conditional form of the CAPM set out in (3) above, which implies that industry betas might vary through time in response to variables known to predict market returns. For example, interest rates may have a greater or lesser impact on industry betas depending on the average gearing levels in the industry. The second is a conditional form of the 3FM, which allows industry beta to vary as either market capitalisation or book-to-market ratio varies. The logic here is that as an industry's relative size grows, its factor loading on SMB should fall. As an industry's book-to-market ratio increases, the slope on HML should increase as the industry book-to-market ratio increases, since in the Fama-French model this is an indication of relative financial distress. Thus under the conditional version of the 3FM described in (4) above, the slope of the $s 2$ coefficient should be negative whilst the slope of the $h 2$ coefficient should be positive.

Table 5 gives the results from these conditional regressions. Table 5a presents the conditional CAPM results, and we observe that all betas are significantly positive. The

\footnotetext{
${ }^{6}$ For the regulated industries, the results with regard to factor exposures are statistically somewhat stronger than those from the static model reported above. Telecoms are unaffected, but Electricity and Gas and Water have significant HML exposures. All three industries exhibit significant time variation in betas and both Electricity and Gas \& Water show evidence of time variation in HML exposure. Last, note that these two industries have betas that are significantly less than 1.0.
} 
conditioning factors exhibit some modest explanatory power, notably the Treasury Bill rate. For this variable, four out of 35 industries show betas that have a significant positive association with the rate, and eight industries have a significant negative association. Note that one of the industries that exhibit this positive association is regulated, rising to two if the cut-off is the 10\% confidence level (Ind 27 and 28). The term structure (long minus short rate) has a weaker role to play (three positive and four negative, and again two of these are the same regulated industries) but it is worth noting that the signs on the coefficients are always consistent when either one or the other variable exhibits significance. It seems that interest rate variables have a significant role to play in predicting beta, and the mean adjusted R-squared from the regressions is $34 \%$ (as opposed to $32 \%$ from the static model in Table 3). Taken as a whole, these results are compatible with some predictable time variation in beta. ${ }^{7}$

The conditional version of the 3FM in Table $5 \mathrm{~b}$ shows only a marginal improvement in adjusted R-squared (36\%) compared to the static model (35\%). However, whilst 14 of the s2 coefficients exhibit significance, six are positive whereas in theory they should be negative. For HML, the h2 coefficients should be positive. Unfortunately, only two industries show significant positive coefficients, and two show significant negative coefficients. A simple count of the signs shows that 19 of the SMB and 17 of the HML coefficients have the expected sign in each case. So whilst the results from Tables 4 and 5 show some inter-temporal variability in factor loadings for SMB and HML, there is no compelling evidence that this variability has anything to do with any underlying changes in industry size or book-to-market ratios.

\footnotetext{
${ }^{7}$ Note that for the regulated industries the interest rate coefficients in the rolling CAPM are consistent with the signs of the Newey-West dummy variable coefficients in Table 5.
} 


\subsection{Predictive properties of the models}

In this section, we examine the ability of our various models to predict future returns and future factor loadings. Given the evidence on time varying factor loadings, we also include a model which sets all industry betas equal to unity. Unlike Fama and French (1997), we do not estimate forecast errors for the one month horizon, as we believe regulators and industry users are more concerned with long horizon forecasts. Neither do we include intercept terms in our forecasts. We undertake two tests here. The first estimates the required return forecast error three years and five years forward, using estimates of coefficients obtained at time $t$ and the realised industry and factor returns for each month from time $t+1$ to time $t+36, t+60$. The second test directly measures the forecast error in the underlying coefficients.

Table 6 presents the 36 and 60 month cost of capital prediction errors. The figures are broadly comparable with those shown in the lower panels of Fama and French (1997, Table 6, pp 168-9). For each of the two panels, the top three rows show the forecast errors (mean, mean absolute, and standard deviation of forecast errors) for the rolling models, static models and conditional models respectively. The general picture to emerge is that whilst mean errors are relatively small, absolute errors and standard deviation of errors are typically larger than those reported by Fama and French by a factor of roughly two thirds. This is perhaps an unsurprising result given that our industry portfolios necessarily contain fewer firms than their US industry equivalents and we estimate our models over a shorter time frame. For the rolling 36 month models, there is little to choose between the CAPM, 3FM and 4FM models, although the CAPM gives the lowest mean standard error and the 4FM the highest. We cannot directly compare predictive power between the R\&D 4-factor model and the others, because of the shorter time frame, but at first sight the model appears to have quite high errors. However, we know that there may be a particular problem with the time period over which the R\&D model predictions are being tested, because of the initial run-up in TMT stock prices followed by the subsequent decline in these prices post-millennium. The fair comparison is therefore with the FF3F model predictions over the same period that the R\&D model can be estimated. Error rates are now broadly comparable, with the FF3F model performing marginally better over 36 months. 
With the static model we add the beta one (or market adjusted return) model, which it turns out has the poorest predictive power both in mean absolute error (MAE) and mean standard error (MSE) terms. There is no clear winner, but we note that the static 4F model comes out slightly ahead of the static FF3F model, with both beating the CAPM, and in all cases the static models outperform their rolling counterparts. The conditional versions of the CAPM and 3FM do not appear to improve on their static equivalents, but in the case of the FF3F model the conditional version does appear to out-perform the rolling version.

Looking at the 60-month ahead forecasts, for the rolling models the pecking order seems to favour the CAPM, but only marginally so. Whether the FF3F or 4F models are next in line depends on whether one looks to the MAE or MSE as indicators. Over the R\&D model period, at the 60-month horizon the R\&D four factor model now gives a lower mean error and slightly lower MAE than the FF3F model, but has a slightly higher MSE. For the static models, the lowest MAE is again associated with the 4F model, with the FF3F model coming in ahead of the CAPM. However, despite the short estimation period the lowest MSE is associated with the static R\&D model, although it has a high mean error, as might be expected with the short time frame and TMT "bubble" effects referred to above. The conditional CAPM has a poor performance compared to the static and rolling versions of the CAPM, and also to the other models. By contrast, the conditional FF3F model does better than the rolling version, but is still poorer than the simple static model. Last, note that MAR or "Beta one" model performs worse (i.e. has higher MAE and MSE) than any of the factor models assessed at the 60-month horizon. In general, the scale of the errors is, of course, disappointing, but the implication is that any of these factor models give better predictions of the cost of capital than the alternative of simply giving up and assuming beta equals one for all industries. The fact that this alternative gives consistently the worst estimates is an observation that has interesting regulatory implications.

Finally, in Table 7, we present the errors for the estimated coefficients 60 months ahead, i.e. the errors from forming an estimate of the slope at time $t+60$ from the observed slope at time $t$. Looking at such estimates is important because it isolates whether the prediction errors in Table 6 arise from poor estimation of the factor loadings, or from the models failing to predict market prices. In general, the size of the 
errors is somewhat troubling, with a mean absolute error for beta of around 0.27 to 0.28 (whether in the context of the CAPM, 3FM or 4FM) and a standard error of the estimate of around 0.3. The errors in estimating the factor loadings for the SMB, HML and WML factors are, if anything, even more alarming. Further tests (not reported in this paper for space reasons, but available from the authors on request) use the observed 60-month coefficient for any month and use this to predict the coefficient 60 months ahead (i.e. for a non-overlapping data period). The results confirm that past rolling estimates have poor predictive power for future rolling estimates. ${ }^{8}$ However, although results are not strictly comparable because of the different time periods studied, note that the RDMNRD factor slopes appear to be more predictable than the SMB and HML factor slopes in that model. This seems to reinforce the conjecture above that the errors reported in Table 6 from this model have more to do with price variability than with any unreliability in forecasting factor loadings.

Taken as a whole, these results in Table 7 imply that rolling regressions give some very noisy estimates of the future factor loadings in general, and SMB and HML factor loadings in particular, and should certainly motivate the search for better estimation techniques. Candidates might include mean reverting models, or more sophisticated estimates based on weekly or daily (as opposed to monthly) returns. However, it may be the case that using high-level industry definitions could be a source of some of the observed parameter instability problems. If market entry and exit occurs, and/or if the nature of the make up of the industry changes, the betas of individual firms could remain unchanged, but the industry beta could vary substantially. ${ }^{9}$ Further tests, not reported here, using 20 industries and also equally-weighted rather than value-weighted returns do not show any improvement in mean estimation errors. What we cannot rule out is whether much finer industry definitions would yield better estimates.

\footnotetext{
${ }^{8}$ For example, under the 3FM a regression of the forward beta (SMB or HML loading) on the lagged beta (SMB and HML loading) result in mean adjusted R-squared values of $15.2 \%, 13.7 \%$ and $12.8 \%$ respectively.

${ }^{9}$ As an example, consider Industry 26. This covers fixed and mobile communications. Given the privatisation of BT, and the move from fixed line to mobile telecommunications, it is not surprising that the industry beta shows some time variation.
} 


\section{CONCLUSIONS}

Overall, the picture that emerges from this UK research is every bit as bleak as that which comes from the Fama and French US study. Cost of capital is estimated with large errors, as are the slope coefficients in either the CAPM or three factor models. Whether the latter is better than the traditional CAPM is difficult to judge. The errors in estimating cost of capital three and five years forward are very marginally better than those obtained from the CAPM. On the negative side, the SMB and HML factor slopes have a great deal of variability through time, and unlike the position that obtains in the US research, there is little to suggest that the variation occurs in such a way as to reflect size and book-to-market changes in industries. Our results can also be read alongside those of Michou et al (2007), which show that results are also sensitive to the method used for factor construction.

We see nothing in our results to suggest that the addition of a fourth factor, momentum, has anything significant to contribute. A new model, that of Al-Horani et al (2003), clearly has potential in that over the limited period for which data is available it yields return errors not dissimilar to those found under the FF3F model, whilst at the same time having slope coefficients on the fourth $R \& D$ factor that seem to be relatively stable and which are more predictable than either the SMB or HML slope coefficients.

In terms of policy implications from this work, it is interesting to note that some regulatory authorities have employed the CAPM and have estimated the equity beta for firms and industries using, in effect, rolling monthly betas. Whilst our results that suggest rolling CAPM estimates give predicted returns no worse than those which are obtained from more complex models might be a source of comfort for such regulatory authorities, our work also implies that better forecasts of beta would be highly desirable, and certainly provides a motivation for further work in this area.

Our study also raises additional interesting issues for future research. In particular, one challenge is to seek an explanation for the observed instability in the factor slope coefficients, and to explore the degree to which these are associated with variables which could theoretically explain such variation, for example changes in gearing and changes in industry composition. Following Michou et al (2007), a further line of 
research might be to investigate whether our results are sensitive to factor construction methods. In particular, an interesting question would be whether alternative specifications of the R\&D factor are capable of yielding more powerful models of the cross-section of UK returns.

One clear message that does emerge from this research, for the CAPM and the alternative factor models investigated, is that despite the noisiness of the estimates, all outperform the simple alternative of assuming that beta is equal to one for all firms. Furthermore, beta estimates for the main regulated utility industry groupings used in this paper are reliably less than one, although we also present evidence that betas are time varying, and appear to be associated with interest rate risk. In addition, these industries have some exposure to the HML factor. Taken as a whole, we hope that these results may help to stimulate an interesting debate amongst regulators.

\section{REFERENCES}

Al-Horani, A., P. F. Pope and A. W. Stark (2003), 'Research and Development Activity and Expected Returns in the United Kingdom', European Finance Review Vol. 7, pp. 27-46.

Ashton, D. and M. Tippett (1998), 'Systematic Risk and Empirical Research', Journal of Business Finance and Accounting, Vol. 25, 9 \& 10 (December), pp. 1325-1356.

Cahart, M. (1997), 'On Persistence in Mutual Fund Performance', Journal of Finance, Vol. 52, pp. 57-82.

Dimson, E., P. Marsh and M. Staunton (2002), Triumph of the Optimists: 101 Years of Global Investment Returns, Princeton New Jersey: Princeton University Press.

Dimson, E., P. Marsh, and M. Staunton (2006), 'The Worldwide Equity Premium: A Smaller Puzzle', http://ssrn.com/abstract $=891620$.

Dimson, E., P. Marsh and M. Staunton (2007), Global Investment Returns Yearbook, 2007, London: ABN AMRO/ LBS.

Fama, E. F. and K. R. French (1993), 'Common Risk Factors in the Returns on Stocks and Bonds', Journal of Financial Economics, Vol. 33, pp. 3-56. 
Fama, E. F. and K. R. French (1995), 'Size and Book-to-Market Factors in Earnings and Returns', Journal of Finance, Vol. 50, pp. 131-156.

Fama, E. F. and K. R. French (1996), 'Multifactor Explanations of Asset Pricing Anomalies', Journal of Finance, Vol. 50, pp. 131-155.

Fama, E.F. and K. R. French (1997), 'Industry costs of equity', Journal of Financial Economics, Vol. 43, pp. 153-193.

Ferson, W.E. and R.W. Schadt (1996), 'Measuring Fund Strategy and Performance in Changing Economic Conditions', Journal of Finance, Vol. 51, No. 2, pp. 425-61.

Gregory, A. (2007), 'How Low is the UK Equity Risk Premium?', University of Exeter/Xfi Centre for Finance and Investment Working Paper.

Gregory, A., R. D. F. Harris and M. Michou (2001), 'An Analysis of Contrarian Investment Strategies in the UK' Journal of Business Finance and Accounting, Vol. 28/9\&10, pp. 1931-1228.

Gregory, A., R. D. F. Harris and M. Michou (2003), 'Contrarian Investment and Macroeconomic Risk' Journal of Business Finance and Accounting, Vol. 30, 1\&2, pp. 213-255.

Gregory, A. and J. Rutterford (2001), 'Industry cost of capital in the UK', CIMA Research Update, pp. 6-7, Spring/Summer 2001, London, Chartered Institute of Management Accountants.

Gregory, A and J.M. Whittaker, (2007) 'Performance and Performance Persistence of Ethical Unit Trusts in the UK', Journal of Business Finance and Accounting, Sept/Oct 2007, pp. 1327-1344.

Jaganathan, R. and Z. Wang (1996), 'The Conditional CAPM and the Cross-Section of Expected Returns', Journal of Finance, Vol. 51, No. 1, March pp. 3-54.

Jegadeesh, N. and S. Titman (1993), 'Returns to Buying Winners and Selling Losers: Implications for Stock Market Efficiency', Journal of Finance, Vol. 48, pp. 65-91.

Jegadeesh, N. and S. Titman (2001), 'Profitability of momentum strategies: an evaluation of alternative explanations', Journal of Finance, Vol. 56, pp. 699-720.

Kim, D. (1995), 'The Errors in the Variables Problem in the Cross-Section of Expected Stock Returns', Journal of Finance, Vol. 50, No. 5, December pp. 1605-1634.

Kothari, S.P., J. Shanken and R.G. Sloan (1995), 'Another Look at the Cross-section of Expected Returns' Journal of Finance. 50(1), pp. 185-224.

Lesmond D., M.J Schill and C. Zhu, (2004) 'The Illusory Nature of Momentum Profits', Journal of Finance, Vol. 71, pp. 349-380. 
Liu, W. (2006), 'A liquidity-augmented capital asset pricing model', Journal of Financial Economics, Vol. 82, pp. 631-671.

Liu,W., N. Strong and X. Xu (1999), 'The Profitability of Momentum Investing', Journal of Business Finance and Accounting, Vol.26, pp. 1043-1091.

Michou, M., S. Mouselli and A.W Stark (2007), 'Estimating the Fama and French Facors in the UK: An Empirical Review', Manchester Business School Working paper series, http://www.mbs.ac.uk/research/workingpapers/index.aspx

Newey, W. K. and K. D. West (1987), 'A Simple, Positive Semi-Definite, Heteroskedasticity and Autocorrelation Consistent Covariance Matrix', Econometrica, Vol. 55, pp. 703.

Tonks, I. and M. Hon (2003), 'Momentum in the UK Stock Market', Journal of Multinational Financial Management, Vol. 13, No. 1, February 2003, pp. 43-70.

Roll, R. and S. Ross (1994), 'On the Cross Sectional Relation Between Expected Returns and Betas', Journal of Finance, Vol. 49, pp. 101-122.

Vivian, A. (2007), 'The UK Equity Premium: 1901-2004', Journal of Business Finance and Accounting, Vol. 34, 9\&10, pp. 1496-1527. 
Table 1

Industry summary statistics

Table 1 shows mean and median monthly returns, the number of monthly observations for the industry, standard deviation of monthly returns and the logs of the industry average book-to-market ratios and market capitalisations

\begin{tabular}{|c|c|c|c|c|c|c|}
\hline Industries & Mean & Median & Stdev & Nof Obs & $\begin{array}{l}\text { Ln } \\
\text { B/M }\end{array}$ & $\begin{array}{l}\text { Ln } \\
\text { MV }\end{array}$ \\
\hline Oil \& Gas & $1.47 \%$ & $1.59 \%$ & $7.66 \%$ & 366 & -0.51 & 6.90 \\
\hline Chemicals & $0.66 \%$ & $0.66 \%$ & $7.26 \%$ & 366 & -0.61 & 5.61 \\
\hline Forestry \& Paper & $2.93 \%$ & $4.07 \%$ & $11.56 \%$ & 366 & -0.67 & 4.32 \\
\hline Industrial Metals & $2.49 \%$ & $3.07 \%$ & $14.83 \%$ & 366 & -1.52 & 5.28 \\
\hline Mining & $1.51 \%$ & $1.77 \%$ & $9.29 \%$ & 366 & -0.54 & 5.61 \\
\hline Construction \& Materials & $1.04 \%$ & $0.50 \%$ & $7.63 \%$ & 366 & -0.46 & 5.17 \\
\hline Aerospace \& Defence & $1.77 \%$ & $1.90 \%$ & $7.43 \%$ & 366 & -0.72 & 5.39 \\
\hline General Industrials & $0.84 \%$ & $0.92 \%$ & $7.27 \%$ & 366 & -0.64 & 5.07 \\
\hline Electronic \& Electrical Equipment & $0.88 \%$ & $0.75 \%$ & $9.97 \%$ & 366 & -0.98 & 4.94 \\
\hline Industrial Engineering & $1.45 \%$ & $1.85 \%$ & $7.97 \%$ & 366 & -0.47 & 4.48 \\
\hline Industrial Transportation & $1.17 \%$ & $1.03 \%$ & $8.42 \%$ & 366 & -0.75 & 5.10 \\
\hline Support Services & $1.22 \%$ & $1.88 \%$ & $6.61 \%$ & 366 & -1.71 & 4.77 \\
\hline Automobiles \& Parts & $0.90 \%$ & $1.11 \%$ & $8.56 \%$ & 366 & -0.16 & 5.68 \\
\hline Beverages & $1.11 \%$ & $1.21 \%$ & $7.18 \%$ & 366 & -1.01 & 6.76 \\
\hline Food Producers & $0.95 \%$ & $1.13 \%$ & $5.91 \%$ & 366 & -0.76 & 5.78 \\
\hline Household Goods & $0.76 \%$ & $0.69 \%$ & $6.78 \%$ & 366 & -0.72 & 4.47 \\
\hline Leisure Goods & $1.16 \%$ & $0.98 \%$ & $8.50 \%$ & 366 & -0.79 & 5.06 \\
\hline Personal Goods & $1.19 \%$ & $1.11 \%$ & $9.02 \%$ & 366 & -0.86 & 5.23 \\
\hline Tobacco & $1.47 \%$ & $1.36 \%$ & $7.47 \%$ & 366 & -0.91 & 7.97 \\
\hline Health Care Equipment \& Services & $1.34 \%$ & $0.97 \%$ & $8.64 \%$ & 366 & -1.32 & 5.17 \\
\hline Pharmaceuticals \& Biotechnology & $1.55 \%$ & $1.25 \%$ & $7.95 \%$ & 366 & -1.77 & 7.12 \\
\hline Food \& Drug Retailers & $0.97 \%$ & $1.09 \%$ & $6.97 \%$ & 366 & -0.96 & 6.03 \\
\hline General Retailers & $1.14 \%$ & $1.27 \%$ & $6.71 \%$ & 366 & -1.02 & 5.52 \\
\hline Media & $1.20 \%$ & $1.69 \%$ & $7.22 \%$ & 366 & -2.09 & 5.33 \\
\hline Travel \& Leisure & $1.31 \%$ & $1.31 \%$ & $6.35 \%$ & 366 & -0.73 & 5.38 \\
\hline Fixed Line Telecommunications + Mobile & & & & & & \\
\hline Telecommunications & $1.80 \%$ & $1.92 \%$ & $9.33 \%$ & 366 & -0.89 & 7.13 \\
\hline Electricity & $1.59 \%$ & $1.50 \%$ & $8.36 \%$ & 344 & -0.69 & 5.63 \\
\hline Gas, Water \& Multiutilities & $1.88 \%$ & $1.87 \%$ & $8.15 \%$ & 264 & -0.33 & 5.03 \\
\hline Banks & $1.50 \%$ & $1.66 \%$ & $6.37 \%$ & 366 & -0.36 & 7.64 \\
\hline Nonlife Insurance & $1.04 \%$ & $1.46 \%$ & $6.93 \%$ & 366 & -0.48 & 6.03 \\
\hline Life Insurance & $1.59 \%$ & $1.60 \%$ & $6.98 \%$ & 366 & -1.02 & 6.76 \\
\hline Real Estate & $1.24 \%$ & $1.77 \%$ & $6.14 \%$ & 366 & -0.03 & 4.84 \\
\hline General Financial & $1.36 \%$ & $1.30 \%$ & $6.19 \%$ & 366 & -0.79 & 4.79 \\
\hline Software \& Computer Services & $0.88 \%$ & $1.43 \%$ & $9.91 \%$ & 366 & -1.59 & 4.61 \\
\hline Technology Hardware \& Equipment & $-0.43 \%$ & $-0.06 \%$ & $11.42 \%$ & 191 & -0.75 & 4.97 \\
\hline
\end{tabular}


Table 2

Monthly factor premia for CAPM, three factor and four-factor models, 6/1975* 12/2005.

RMRF is the market risk premium, SMB is the "Small minus Big" factor, HML is the High book-tomarket minus Low book-to-market factor, WML is a momentum factor (the return on the past "winner" portfolio minus the return on the past "loser" portfolio) and RDMNRD is the R\&D factor calculated as the difference between the average of the value-weighted with $R \& D$ portfolio returns, and the value weighted without $\mathrm{R} \& \mathrm{D}$ portfolio returns. TBR is the Treasury Bill rate

\begin{tabular}{|c|c|c|c|c|c|c|}
\hline & RMRF & SMB & HML & WML & TBR & RD \\
\hline Mean & $0.53 \%$ & $0.01 \%$ & $0.44 \%$ & $0.14 \%$ & $0.68 \%$ & n.a. \\
\hline SD & $4.95 \%$ & $3.10 \%$ & $3.14 \%$ & $2.78 \%$ & $0.26 \%$ & n.a. \\
\hline nobs & 366 & 366 & 366 & 366 & 360 & n.a. \\
\hline SE & $0.26 \%$ & $0.16 \%$ & $0.16 \%$ & $0.15 \%$ & $0.01 \%$ & n.a. \\
\hline \multicolumn{7}{|c|}{ Mean since July '91 } \\
\hline Mean & $0.35 \%$ & $-0.07 \%$ & $0.44 \%$ & $0.02 \%$ & $0.46 \%$ & $1.44 \%$ \\
\hline SD & $4.02 \%$ & $3.69 \%$ & $3.91 \%$ & $3.27 \%$ & $0.13 \%$ & $5.74 \%$ \\
\hline nobs & 174 & 174 & 174 & 174 & 174 & 174 \\
\hline SE & $0.30 \%$ & $0.28 \%$ & $0.30 \%$ & $0.25 \%$ & $0.01 \%$ & $0.44 \%$ \\
\hline \multicolumn{7}{|c|}{ Correlations } \\
\hline RMRF & 1.00 & & & & & \\
\hline SMB & -0.04 & 1.00 & & & & \\
\hline HML & 0.00 & -0.15 & 1.00 & & & \\
\hline WML & -0.11 & -0.20 & -0.23 & 1.00 & & \\
\hline TBR & -0.01 & -0.11 & -0.06 & 0.10 & 1.00 & \\
\hline RD & n.a. & n.a. & n.a. & n.a. & n.a. & n.a. \\
\hline \multicolumn{7}{|c|}{ Correlations since July '91 } \\
\hline RMRF & 1.00 & & & & & \\
\hline SMB & 0.01 & 1.00 & & & & \\
\hline HML & 0.08 & -0.28 & 1.00 & & & \\
\hline WML & -0.28 & -0.17 & -0.26 & 1.00 & & \\
\hline TBR & 0.01 & -0.13 & -0.10 & 0.11 & 1.00 & \\
\hline RD & -0.12 & 0.37 & -0.29 & 0.01 & -0.10 & 1.00 \\
\hline
\end{tabular}

* $12 / 1975$ in the case of the WML factor

* R\&D factor (RDMNRD) is constructed post July 1991 


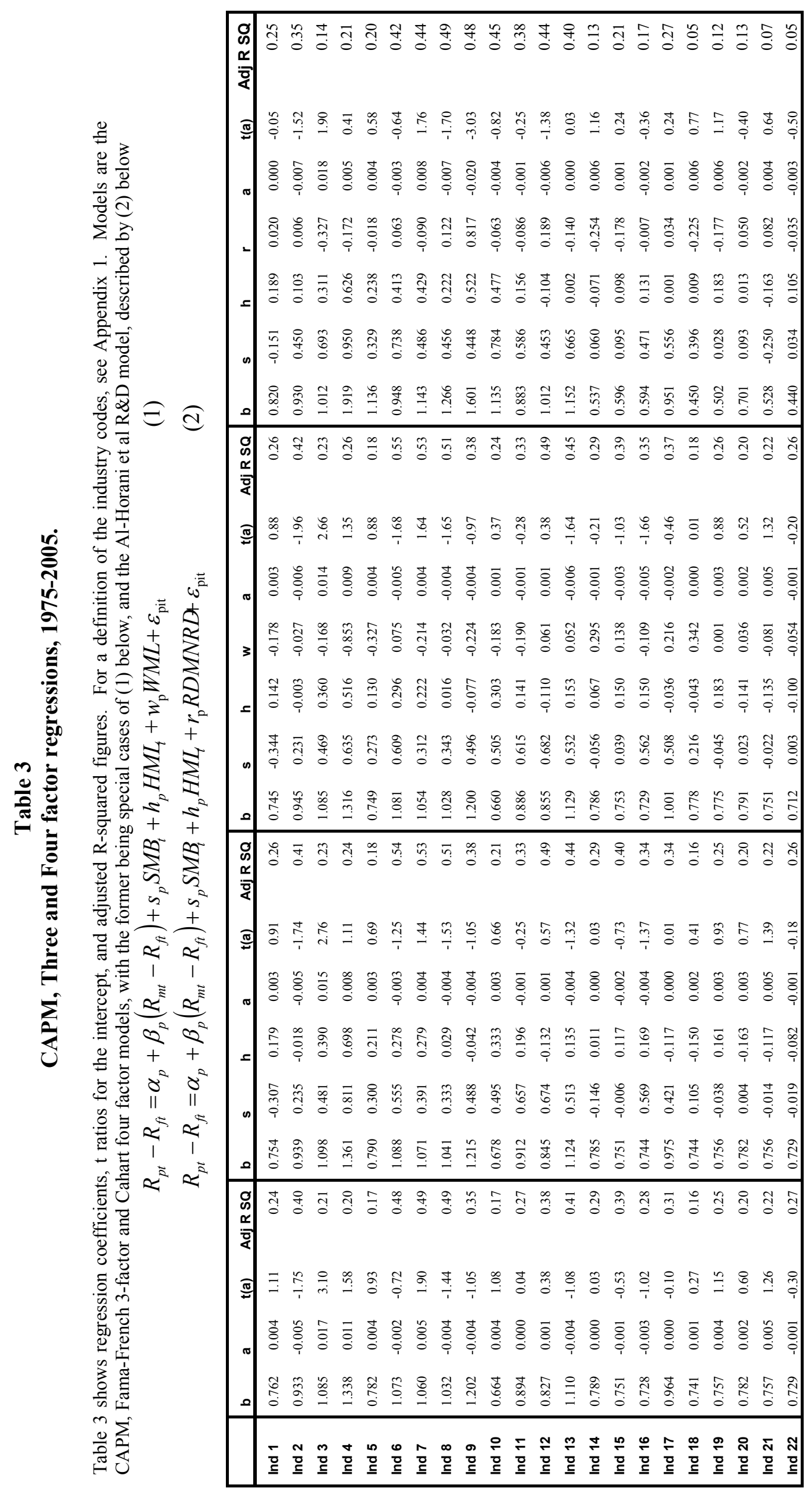




\begin{tabular}{|c|c|}
\hline त̃ & $\overline{\mathrm{m}}$ \\
\hline 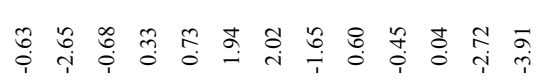 & 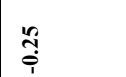 \\
\hline 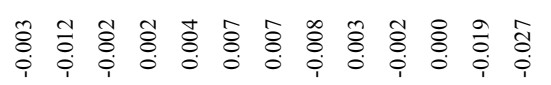 & 厗 \\
\hline 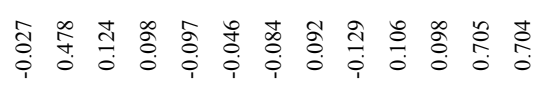 & $\stackrel{0}{g}_{0}^{0} \mathrm{~N}$ \\
\hline 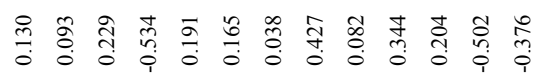 & $\stackrel{2}{\simeq} \infty$ \\
\hline 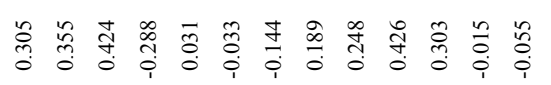 & 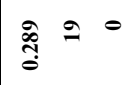 \\
\hline 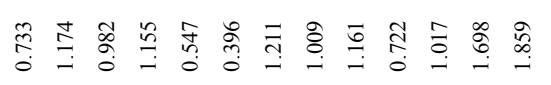 & $\stackrel{\circ}{\circ} \stackrel{\circ}{\circ} 0$ \\
\hline 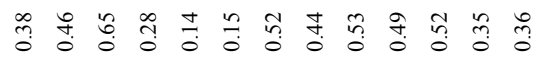 & $\stackrel{\infty}{\infty}$ \\
\hline 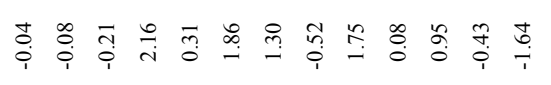 & $\stackrel{m}{5}$ \\
\hline 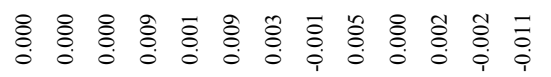 & $\bar{\Xi}^{2}-$ \\
\hline 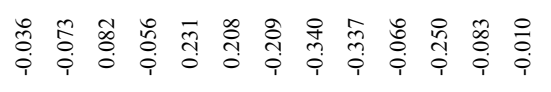 & $\stackrel{\infty}{\stackrel{\leftrightarrow}{i}}+0$ \\
\hline 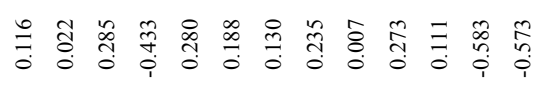 & 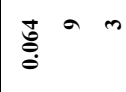 \\
\hline 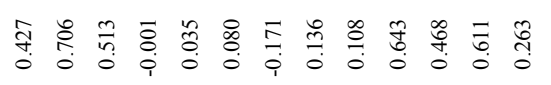 & 突 $2 N$ \\
\hline 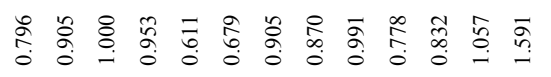 & 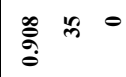 \\
\hline 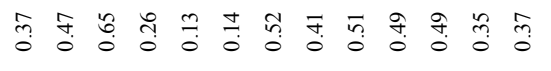 & $\stackrel{\infty}{3}$ \\
\hline 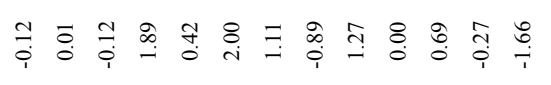 & $\stackrel{9}{9}$ \\
\hline 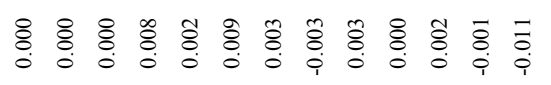 & 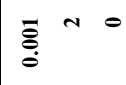 \\
\hline 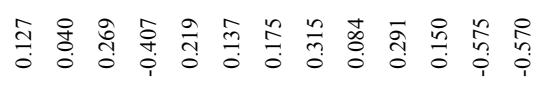 & $\stackrel{n}{g}=m$ \\
\hline 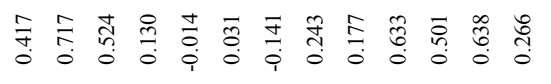 & $\underset{0}{3}$ ส \\
\hline 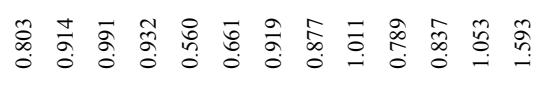 & $\bar{a} \dot{0}^{\infty}$ \\
\hline 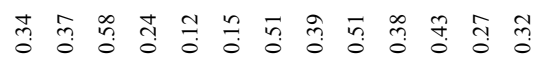 & $\stackrel{\widetilde{3}}{3}$ \\
\hline స̃: & $\stackrel{5}{g}$ \\
\hline 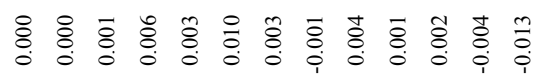 & $\bar{g}^{2}-$ \\
\hline 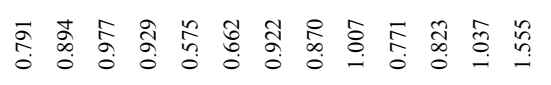 & 育 \\
\hline 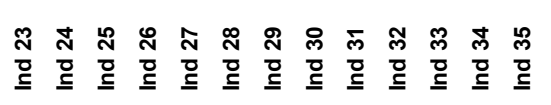 & 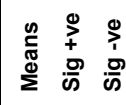 \\
\hline
\end{tabular}




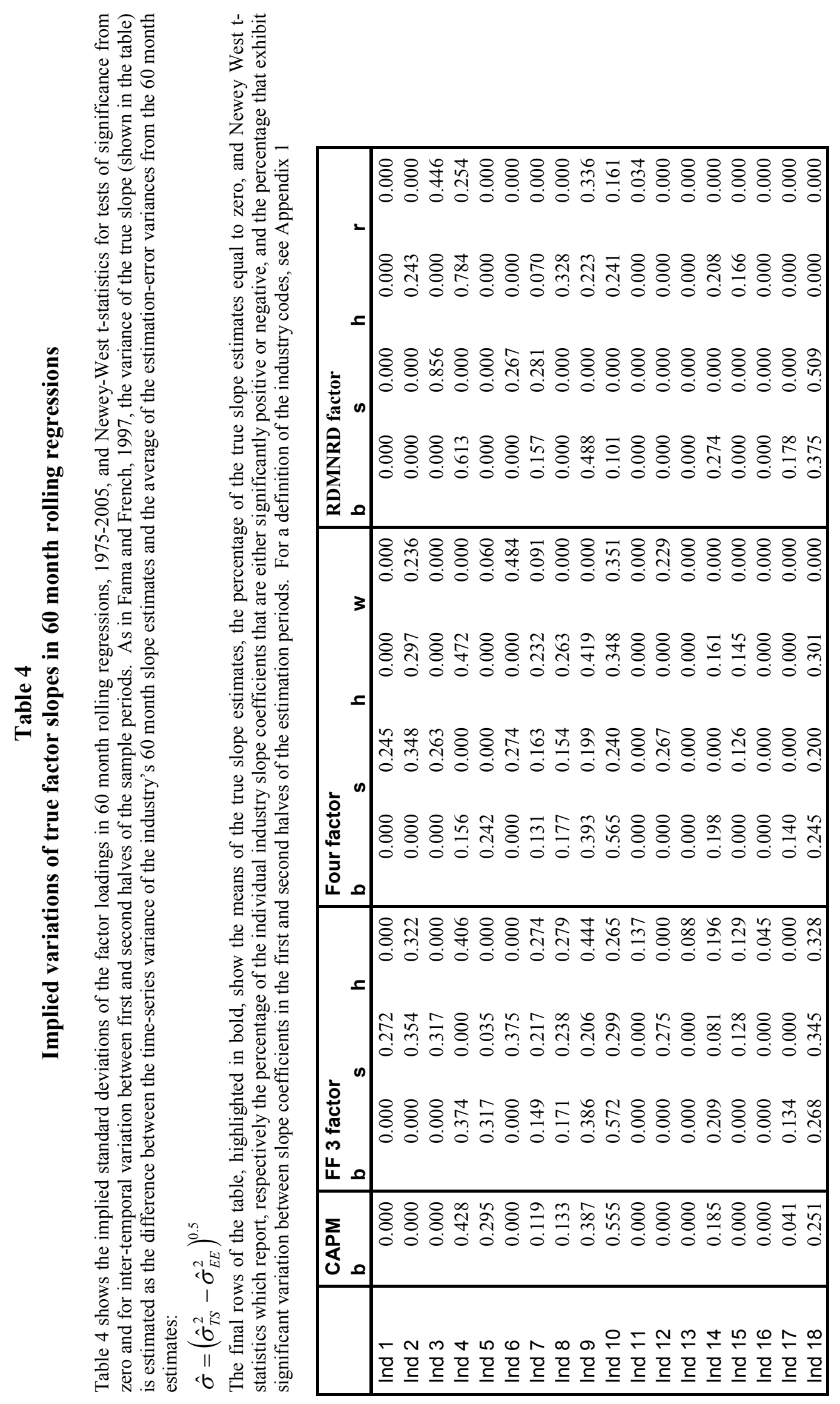




\begin{tabular}{|c|c|c|}
\hline 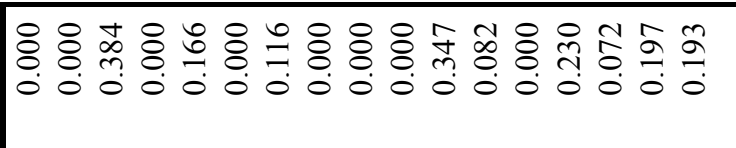 & 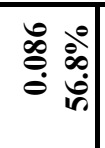 & 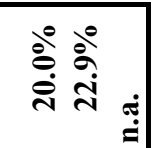 \\
\hline 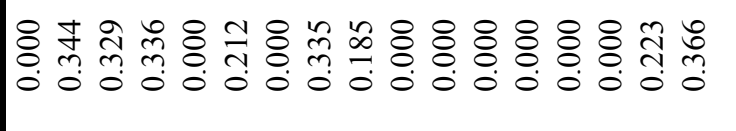 & 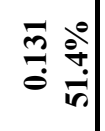 & 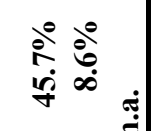 \\
\hline 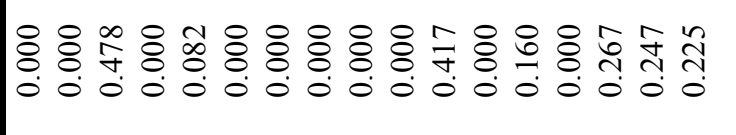 & 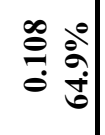 & 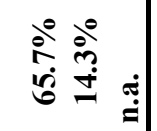 \\
\hline 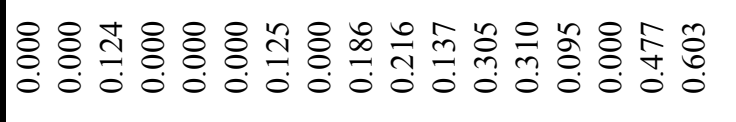 & 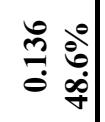 & 高 \\
\hline 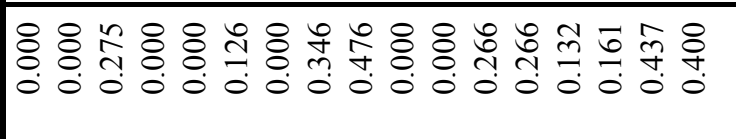 & 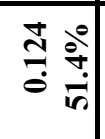 & 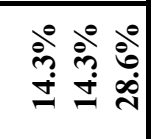 \\
\hline 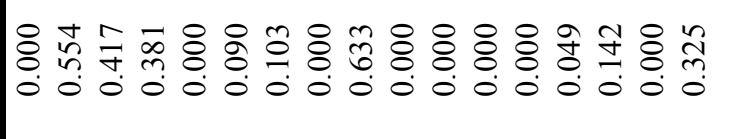 & 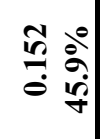 & 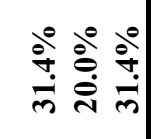 \\
\hline 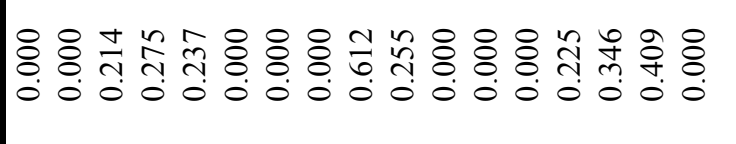 & 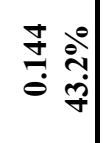 & 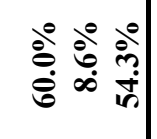 \\
\hline 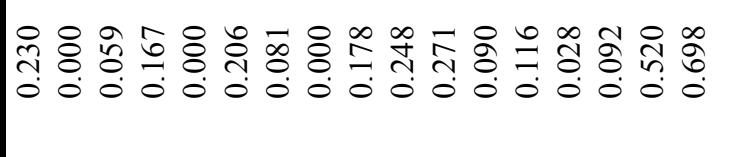 & 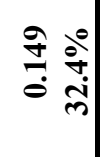 & 递官递 \\
\hline 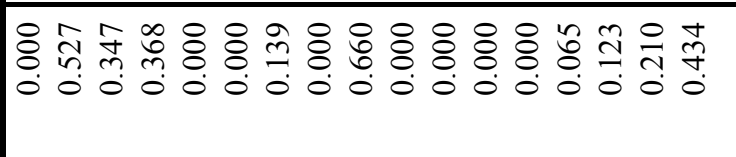 & 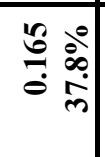 & 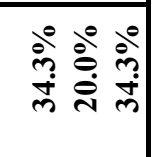 \\
\hline 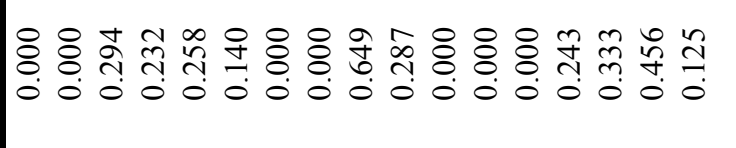 & 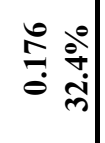 & 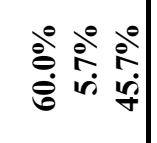 \\
\hline 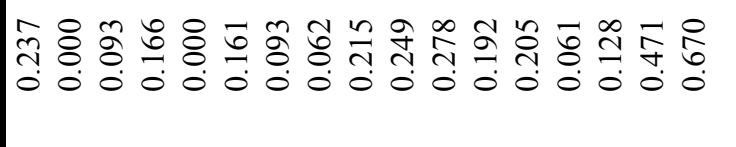 & 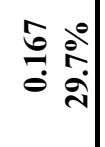 & 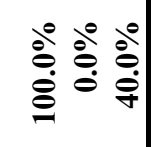 \\
\hline 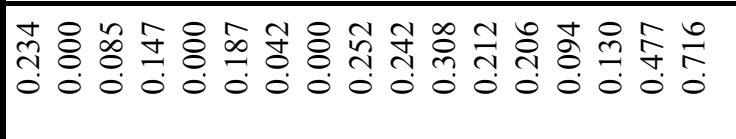 & 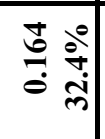 & 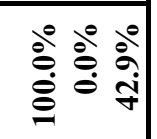 \\
\hline 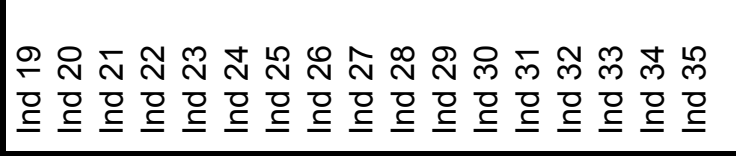 & 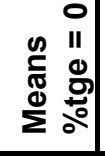 & $\begin{array}{l}0 \\
0 \\
0\end{array}$ \\
\hline
\end{tabular}




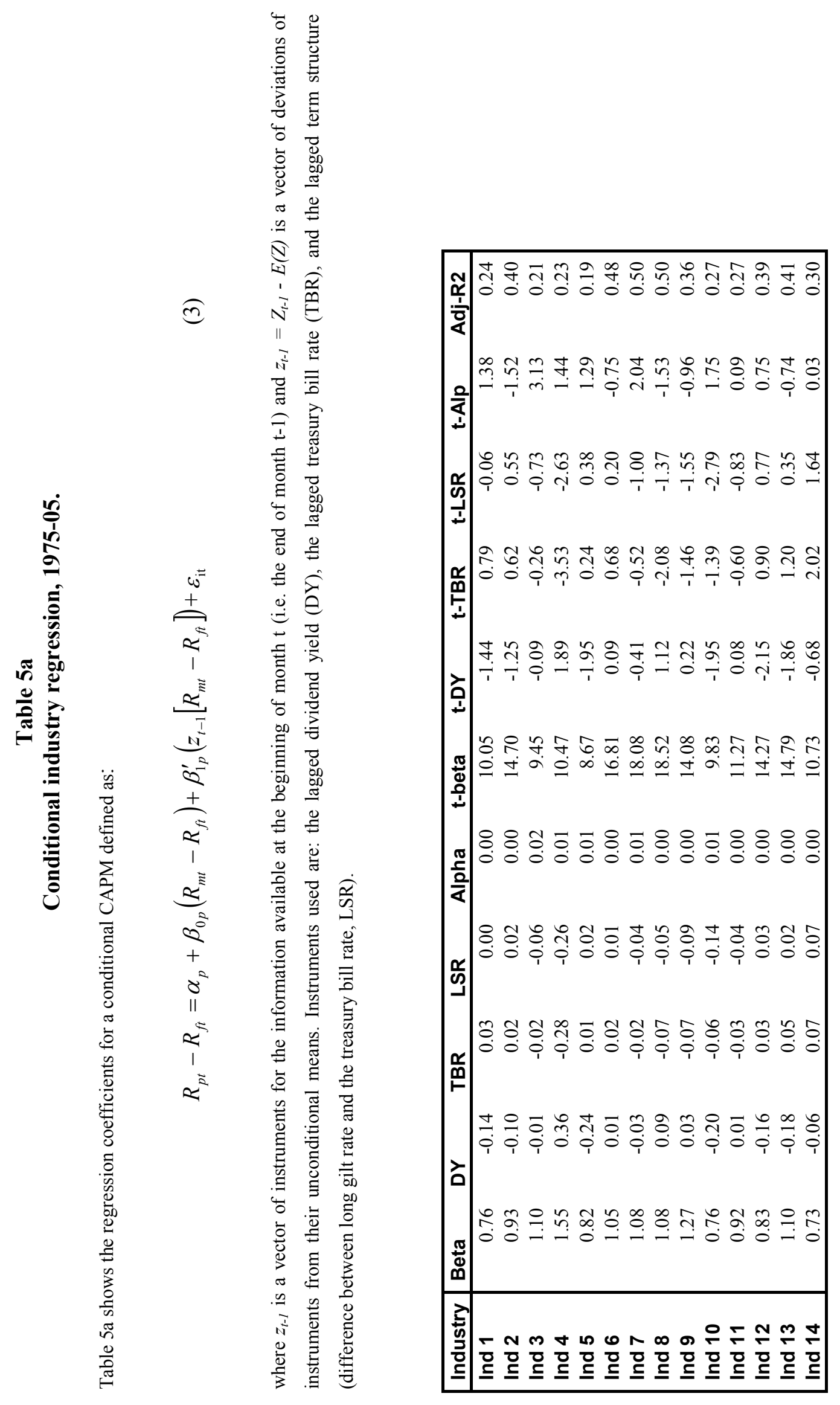




\begin{tabular}{|c|c|}
\hline 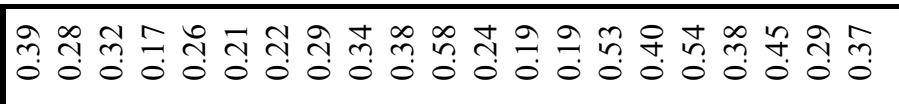 & $\stackrel{\vec{m}}{\overrightarrow{2}}$ \\
\hline 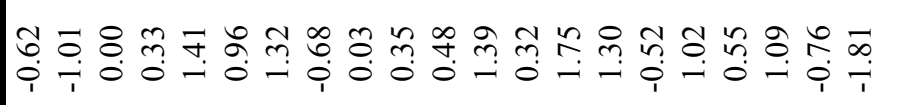 & $\sum_{0}^{\infty} \overbrace{0}^{N}$ \\
\hline 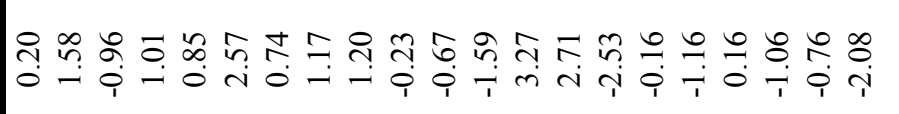 & 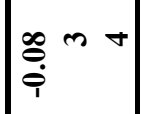 \\
\hline त̦ নุ & $\overbrace{i}^{+\infty}$ \\
\hline 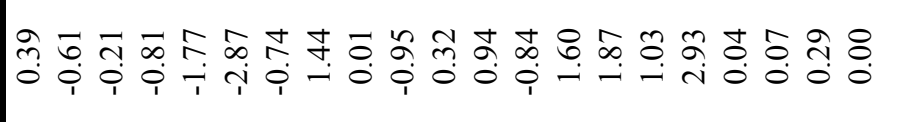 & $\frac{i}{i}-n$ \\
\hline 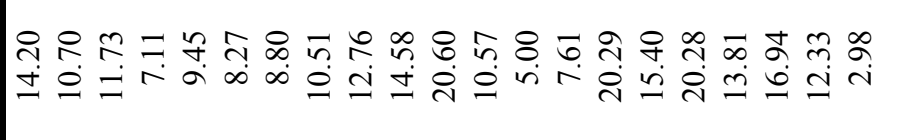 & 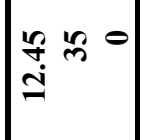 \\
\hline 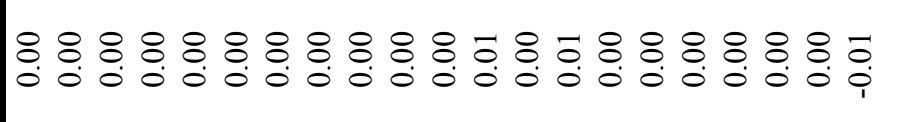 & $\stackrel{0}{8}$ \\
\hline 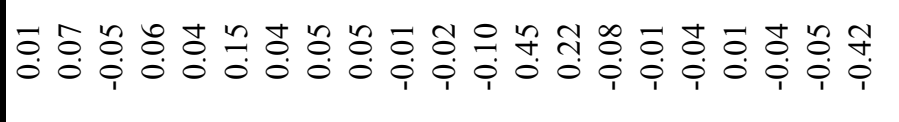 & $\dot{\varphi}_{0}^{+}$ \\
\hline 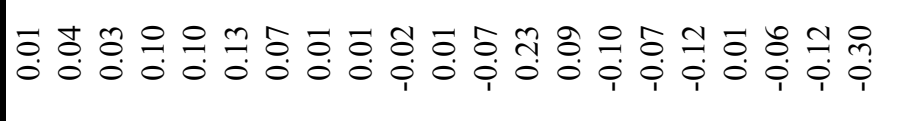 & $\dot{\varphi}_{\dot{i}}$ \\
\hline 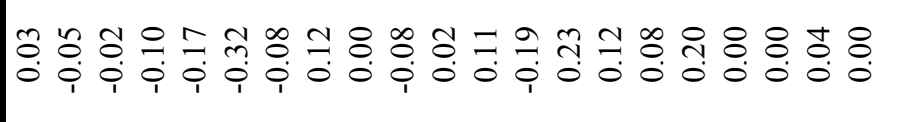 & $\tilde{\overbrace{}}$ \\
\hline 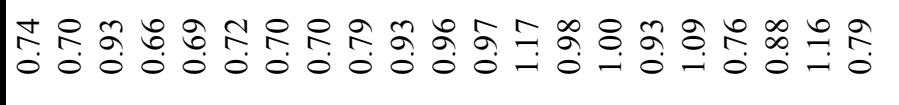 & $\tilde{\delta}$ \\
\hline 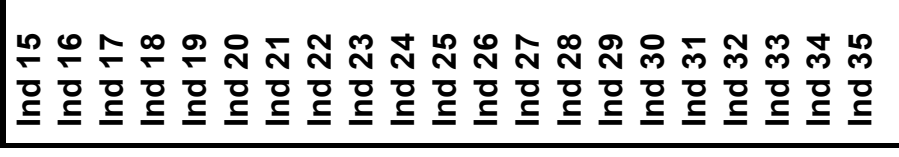 & 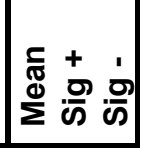 \\
\hline
\end{tabular}




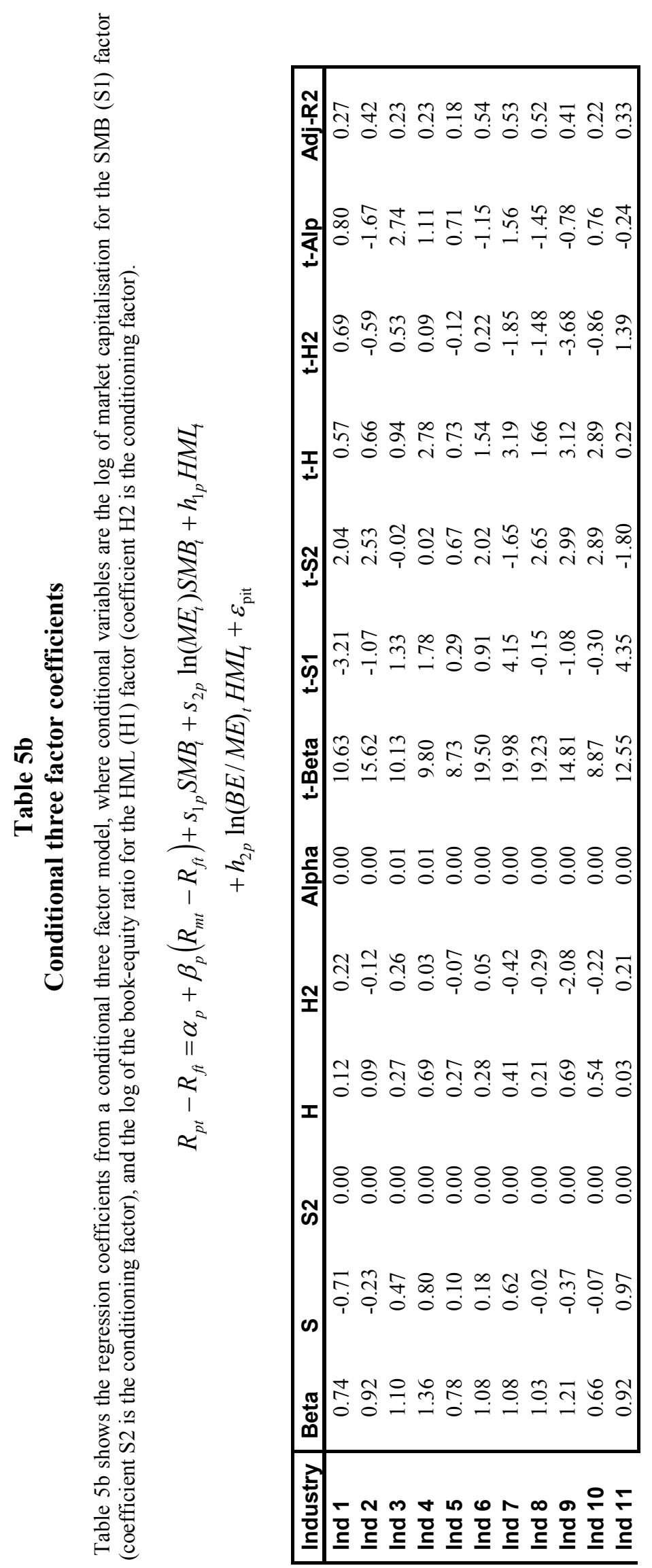




\begin{tabular}{|c|c|c|}
\hline 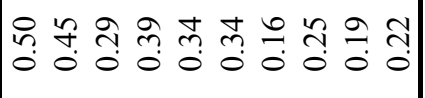 & 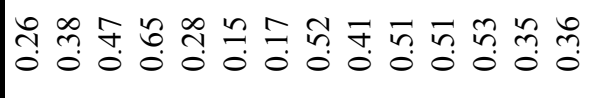 & 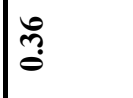 \\
\hline 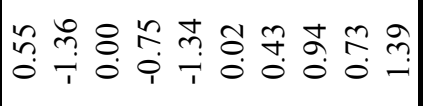 & 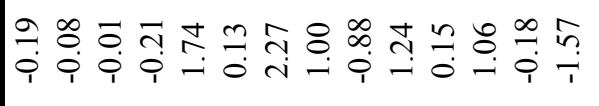 & $\overline{\overbrace{}} \sim 0$ \\
\hline 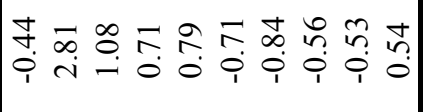 & 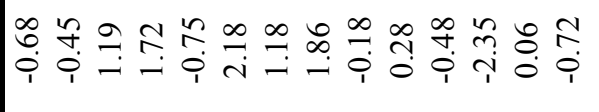 & 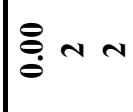 \\
\hline 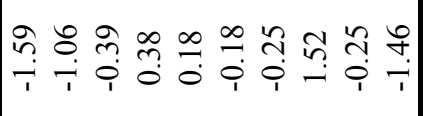 & 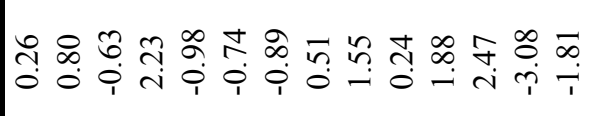 & $\stackrel{g}{\dot{q}} 0-$ \\
\hline 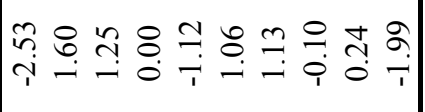 & 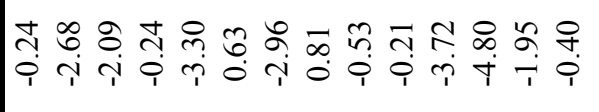 & $\stackrel{\sim}{i} \bullet \infty$ \\
\hline 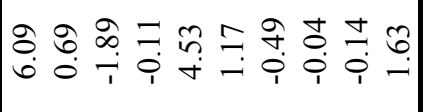 & 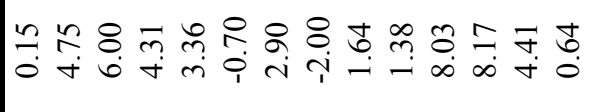 & 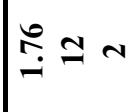 \\
\hline 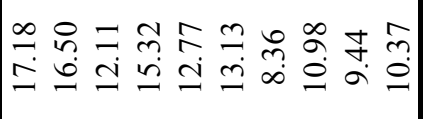 & 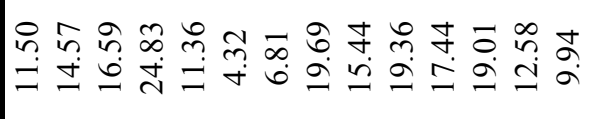 & $\operatorname{m}_{\infty} \infty$ \\
\hline 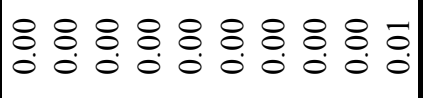 & 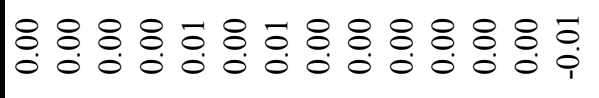 & $\stackrel{8}{\circ}$ \\
\hline 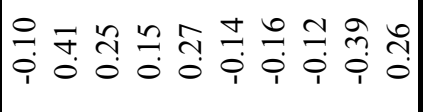 & 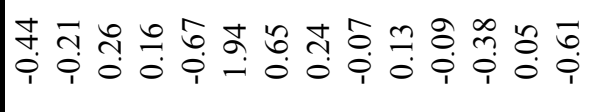 & 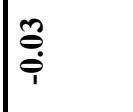 \\
\hline 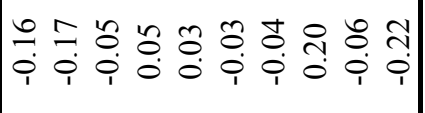 & 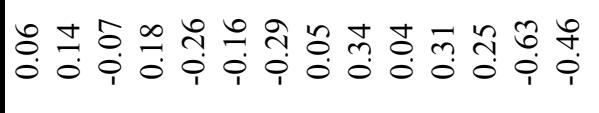 & $\stackrel{\infty}{\stackrel{\infty}{0}}$ \\
\hline 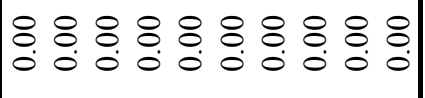 & 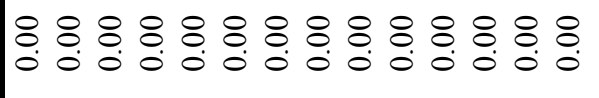 & $\stackrel{8}{\circ}$ \\
\hline 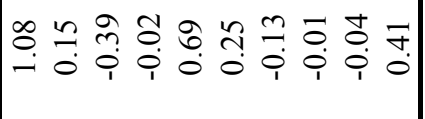 & 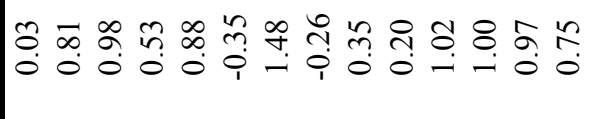 & $\stackrel{n}{\tilde{m}}$ \\
\hline 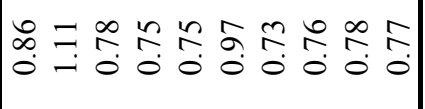 & 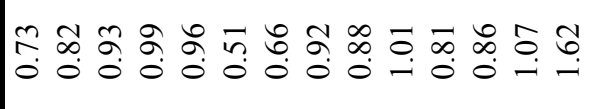 & $\bar{g}$ \\
\hline 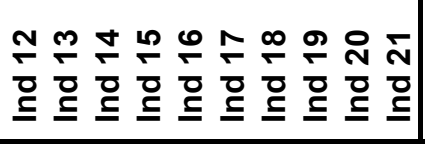 & 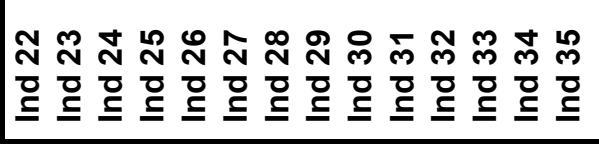 & 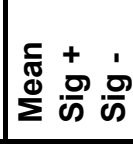 \\
\hline
\end{tabular}




\section{Table 6}

\section{Cost of capital prediction errors}

Table 6 shows the prediction errors resulting from the application of the CAPM, three factor, four factor, simple market adjusted return (i.e. assuming beta equal to unity) and R\&D four factor models variously estimated on a rolling 60 month, static and conditional basis. Prediction errors are estimated as realised return minus the return predicted by the models, excluding any intercept term, for 36 and 60 months ahead. Mean errors, mean absolute errors, and mean standard deviation of forecast errors are all reported.

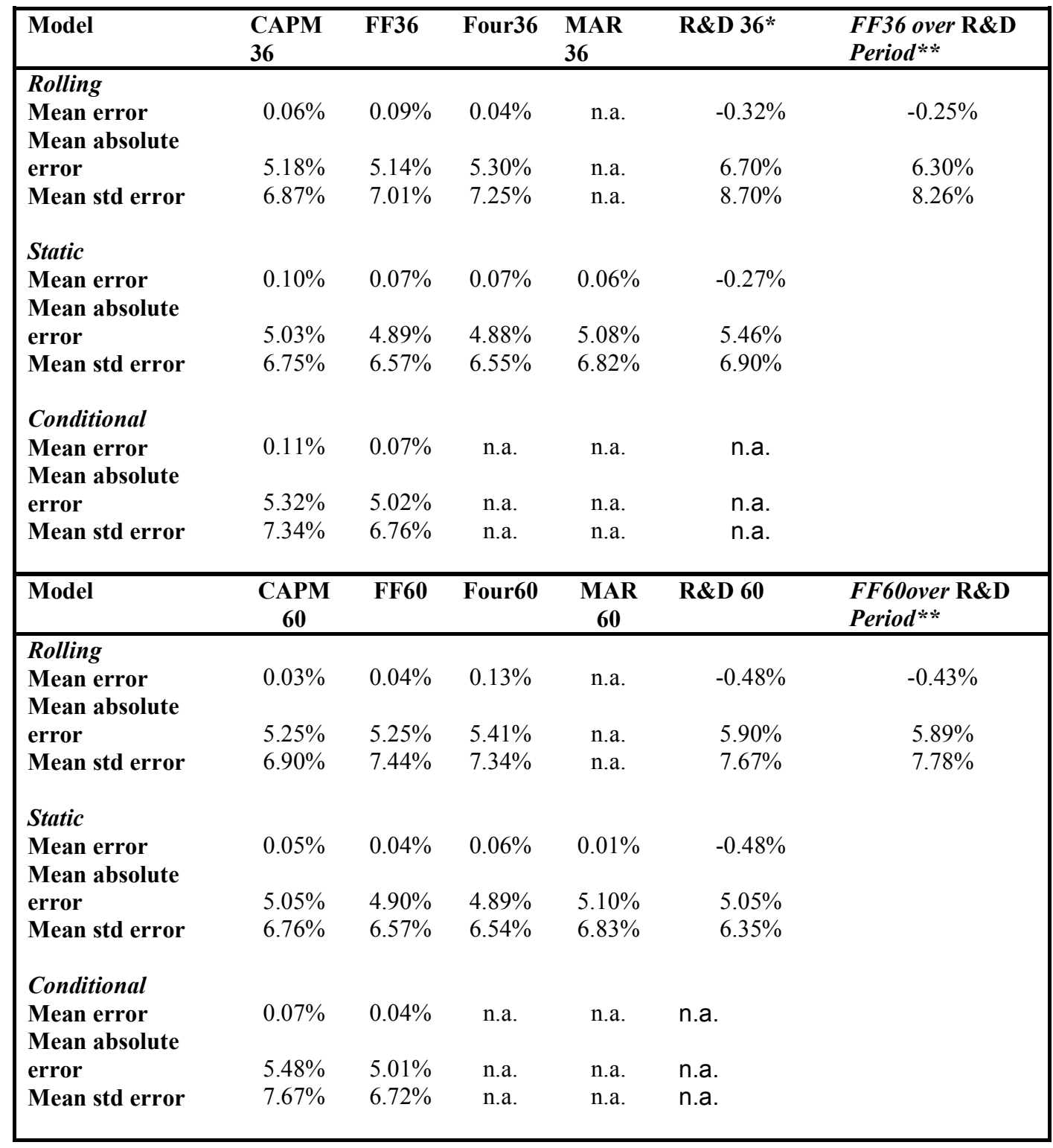

* $R \& D$ is a four factor model where the $R \& D$ factor (RDMNRD) is a replacement of the momentum factor (WML).

** RDMNRD factor is constructed post July 1991, therefore cost of capital prediction errors resulting from the application of $3 \mathrm{FF}$ and RDMNRD factor models for a common period are reported. 


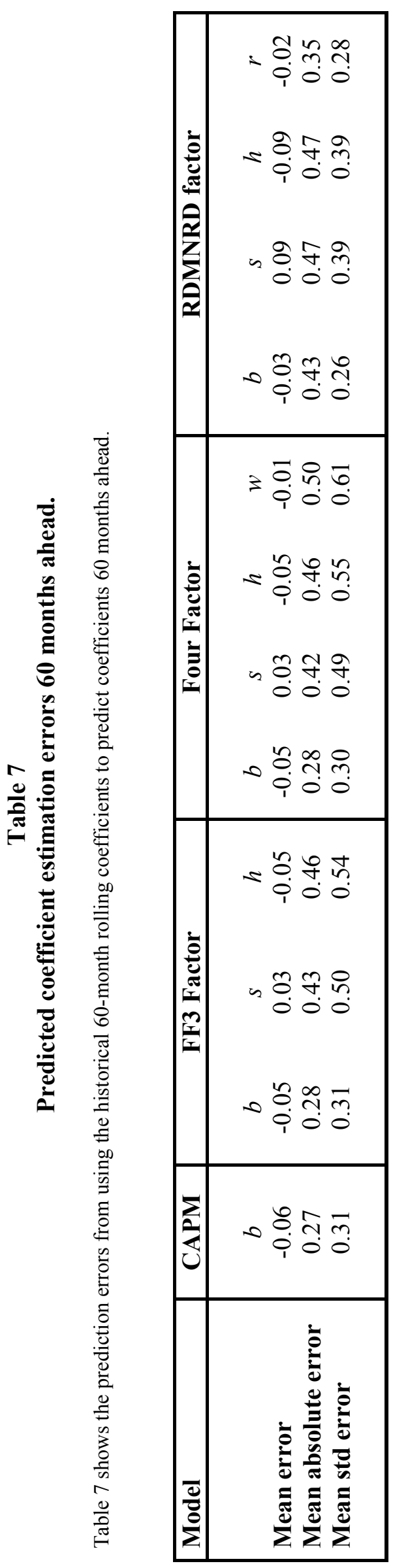




\section{Appendix A: List of industry definitions and codes}

\begin{tabular}{|c|c|}
\hline Industry Code & Industry name \\
\hline 1 & Oil \& Gas \\
\hline 2 & Chemicals \\
\hline 3 & Forestry \& Paper \\
\hline 4 & Industrial Metals \\
\hline 5 & Mining \\
\hline 6 & Construction \& Materials \\
\hline 7 & Aerospace \& Defense \\
\hline 8 & General Industrials \\
\hline 9 & Electronic \& Electrical Equipment \\
\hline 10 & Industrial Engineering \\
\hline 11 & Industrial Transportation \\
\hline 12 & Support Services \\
\hline 13 & Automobiles \& Parts \\
\hline 14 & Beverages \\
\hline 15 & Food Producers \\
\hline 16 & Household Goods \\
\hline 17 & Leisure Goods \\
\hline 18 & Personal Goods \\
\hline 19 & Tobacco \\
\hline 20 & Health Care Equipment \& Services \\
\hline 21 & Pharmaceuticals \& Biotechnology \\
\hline 22 & Food \& Drug Retailers \\
\hline 23 & General Retailers \\
\hline 24 & Media \\
\hline 25 & Travel \& Leisure \\
\hline 26 & Fixed Line Telecommunications + Mobile Telecommunications \\
\hline 27 & Electricity \\
\hline 28 & Gas, Water \& Multiutilities \\
\hline 29 & Banks \\
\hline 30 & Nonlife Insurance \\
\hline 31 & Life Insurance \\
\hline 32 & Real Estate \\
\hline 33 & General Financial \\
\hline 34 & Software \& Computer Services \\
\hline 35 & Technology Hardware \& Equipment \\
\hline
\end{tabular}

